\title{
REDUCING PSEUDOGAPPING TO VP ELLIPSIS
}

\author{
ETSURO SHIMA \\ Yamaguchi University
}

\begin{abstract}
The purpose of this paper is to consider the ellipsis phenomenon called Pseudogapping. Several researchers have assumed that Pseudogapping results from VP ellipsis, with a remnant having moved out of the deleted VP. Given this assumption, I will propose that Pseudogapping involves movement of a remnant to Spec of $\nu \mathrm{P}$ in the overt component, followed by both PF-deletion of a verb projection excluding the remnant and LFmovement of a corresponding phrase out of its antecedent. I will show that this proposal provides a straightforward account of some properties of Pseudogapping that are distinct from VP ellipsis.*
\end{abstract}

Keywords: Pseudogapping, VP ellipsis, contrast effects, backward deletion, locality effects

\section{Introduction}

The interpretation of ellipsis raises important questions for linguistic theory. One of them is to clarify the procedures by which speakers of a language are able systematically to generate appropriate meanings for ellipsis sites. Look at the following two sorts of ellipsis:

(1) a. John will select me, and Mary will, too.

b. John will select me, and Mary will you.

(1a) is a case of VP ellipsis where the verb and object of the second conjunct are missing. On the other hand, (1b) is an instance of Pseudogapping that elides just the verb. One approach to VP ellipsis,

* This paper is a revised and extended version of Shima (2003, 2005). Among the many people who have provided me with valuable comments, I am most grateful to Yoshihito Dobashi, Yoshiki Ogawa, John David Phillips, and Hiroshi Terada. I am also indebted to Henry Atmore for suggesting stylistic improvements. All remaining errors and inadequacies are my own. This work is supported in part by a Grant-in-Aid for Young Scientists (B) from the Ministry of Education, Culture, Sports, Science and Technology, Grant No. 15720112.

English Linguistics 23: 1 (2006) 279-308 - 279-

(C) 2006 by the English Linguistic Society of Japan 
which has been proposed in generative grammar, postulates that an ellipsis site has syntactic structure, but it is deleted from the surface form. This approach gives (1a) the following structure, in which struck-through text indicates deleted material:

(2) John will select me, and Mary will [up-select me], too.

With regard to Pseudogapping, which was first discussed by Sag (1976) and subsequently by Levin (1979), several researchers have recently argued that it is a special case of VP ellipsis and assumed that the right side remnant has moved out of the VP deleted from the surface form (Jayaseelan (1990), Lasnik (1999a, b)). This analysis supplies (1b) with the following structure:

(3) John will select me, and Mary will you ${ }_{1}$ [w select $t_{1}$.

The analysis is theoretically desirable because it can dispense with the conceptually unpleasant notion of "discontinuous deletion." Look at the following examples where far more than just the verb is deleted:

(4) a. The DA proved Jones guilty and the Assistant DA will prove Smith guilty.

b. John gave Bill a lot of money, and Mary will give Susan a lot of money.

(Lasnik (1999a: 153))

The second sentence of (4a) has the following structure under the analysis of Pseudogapping as a special case of VP ellipsis:

(5) $\quad . .$. and the Assistant DA will Smith 1 [vp prove $t$, guilty]

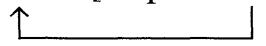

Thus, rejecting the possibility of a deletion rule affecting a discontinuous portion of the structure, the analysis can provide a unified analysis of the seemingly disparate ellipsis phenomena, and hence maximally simple design for the language in question.

If the analysis is to be successful, we should spell out the nature of movement involved in Pseudogapping. In this paper, I will try to address this problem and then propose a new analysis of Pseudogapping. Specifically, given a double-VP structure, I will claim that Pseudogapping involves raising of a remnant to Spec of the upper VP, followed by the deletion of the verb projection excluding the remnant. I will show that the proposed analysis accounts for some properties of Pseudogapping that are distinct from VP ellipsis.

The organization of this paper is as follows: in section 2, I will critically review previous analyses of Pseudogapping. In section 3, I will go into details about the proposal. In section 4 , I will provide further 
support for the proposed analysis. Section 5 is a summary.

\section{Previous Analyses}

Jayaseelan (1990) assumes that Pseudogapping is the product of eliding a VP after Heavy NP Shift (HNPS) has occurred. HNPS is a process that right-adjoins an NP to VP:

(6) John [vp [vp brought $t_{1}$ into the room] [the man who was being interrogated $\left.]_{1}\right]$

He supposes that HNPS brings remnants out of the VP, and then provides (1b) with the following structure:

(7) John will select me, and Mary will [vp [vp select $t_{t}$ ] you ${ }_{1}$ ]

However, it is doubtful that Pseudogapping involves HNPS. Lasnik $(1999 \mathrm{a}, \mathrm{b})$ shows that it does not entirely correlate with the distribution of HNPS. Although the first object in a double object construction is allowed to be a remnant of Pseudogapping, it is resistant to HNPS: ${ }^{1}$

( 8 ) a. ?John gave Bill a lot of money, and Mary will Susan.

b. *John gave $t_{1}$ a lot of money [the fund for the preservation of VOS languages $]_{1}$.

(Lasnik (1999a: 153-154))

The correlation does not hold in the following sentences either:

(9) a. John will select me, and Bill will you.

b.?*Bill will select $t_{1}$ tomorrow you.$\quad$ (Lasnik (1999a: 155))

(9) illustrates that pronouns other than it can be highly acceptable Pseudogapping remnants, whereas they generally resist HNPS. Furthermore, Pseudogapping and HNPS are different in terms of contrastive stress. Consider the following discourse involving HNPS:

(10) Speaker A: Is she suing the hospital that bungled the oper-

1 Lasnik (1999a: 154) reports that the second object makes a poor Pseudogapping remnant, but freely undergoes HNPS:

(i) a. *John gave Bill a lot of money, and Mary will give Bill a lot of advice.

b. John gave Bill $t_{1}$ yesterday [more money than he had ever seen] 1 .

However, some people judge that the second object in a double object construction can be a Pseudogapping remnant once the subjects of the antecedent clause and the Pseudogapping one are identical:

(ii) Although he wouldn't give Bill MONEY, he would give-Bill ADVICE.

I will not explore this dialect variation in this paper.

(Baltin (2003: 226)) 
$\begin{array}{ll} & \text { ation? } \\ \text { Speaker B: } & \text { Yes, she is suing } t \text { in federal court the hospital } \\ \text { that bungled the operation. }\end{array}$ (Lasnik (1999a: 154)) (10) shows that although the shifted NP is sufficiently heavy, it does not receive contrastive stress. On the other hand, Pseudogapping remnants must bear contrastive stress:

(11) Speaker A: Is she suing the hospital that bungled the operation?

Speaker B: *Yes, she is suing the hospital that bungled the operation.

(Lasnik (1999a: 155))

These differences lead Lasnik to claim that a Pseudogapping remnant does not move out of the VP by HNSP.

Instead, he assumes that the remnant is rescued from the VP by raising to Spec of AgrOP, which is an object agreement projection (Chomsky (1991)). Furthermore, he supposes that the subject is generated in the higher VP and the complement is generated in the lower one, and that the two VPs are separated by AgrO (Koizumi (1995)). Then, he gives the antecedent clause in $(1 b)$ the following structure:

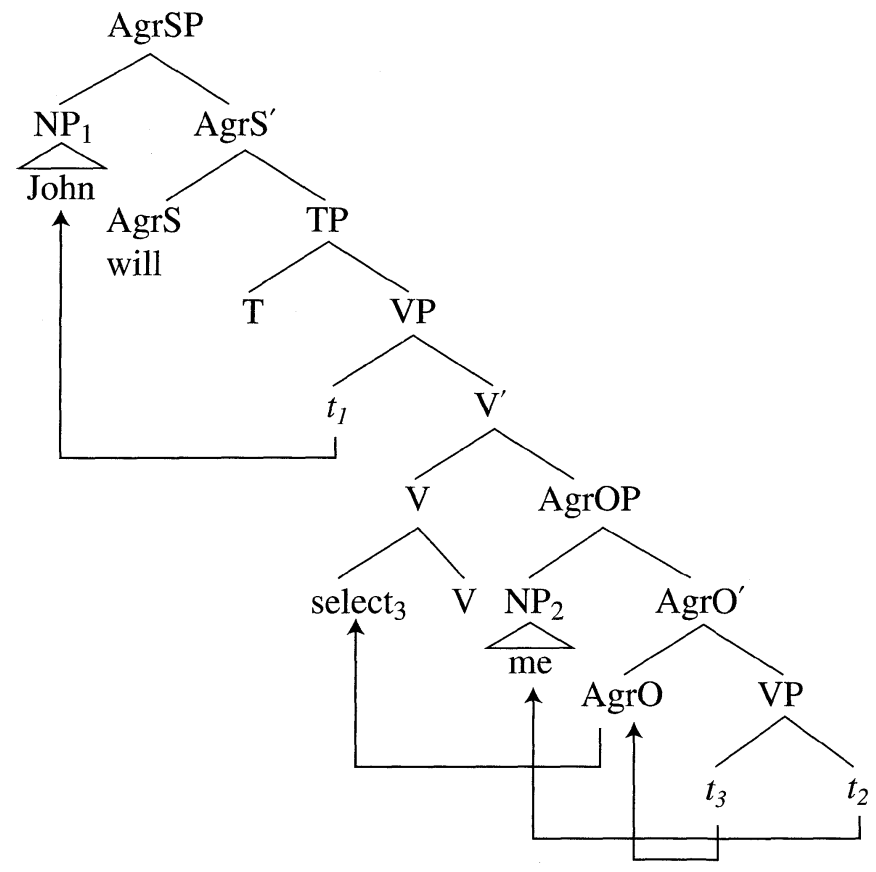


The subject John moves from Spec of the upper VP to Spec of AgrSP, which is a subject agreement projection. The object me raises from the complement position of the lower VP to Spec of AgrOP. The lower V select adjoins to the upper $\mathrm{V}$ through AgrO. Given (12), Lasnik claims that the elided clause in (1b) has the following structure.

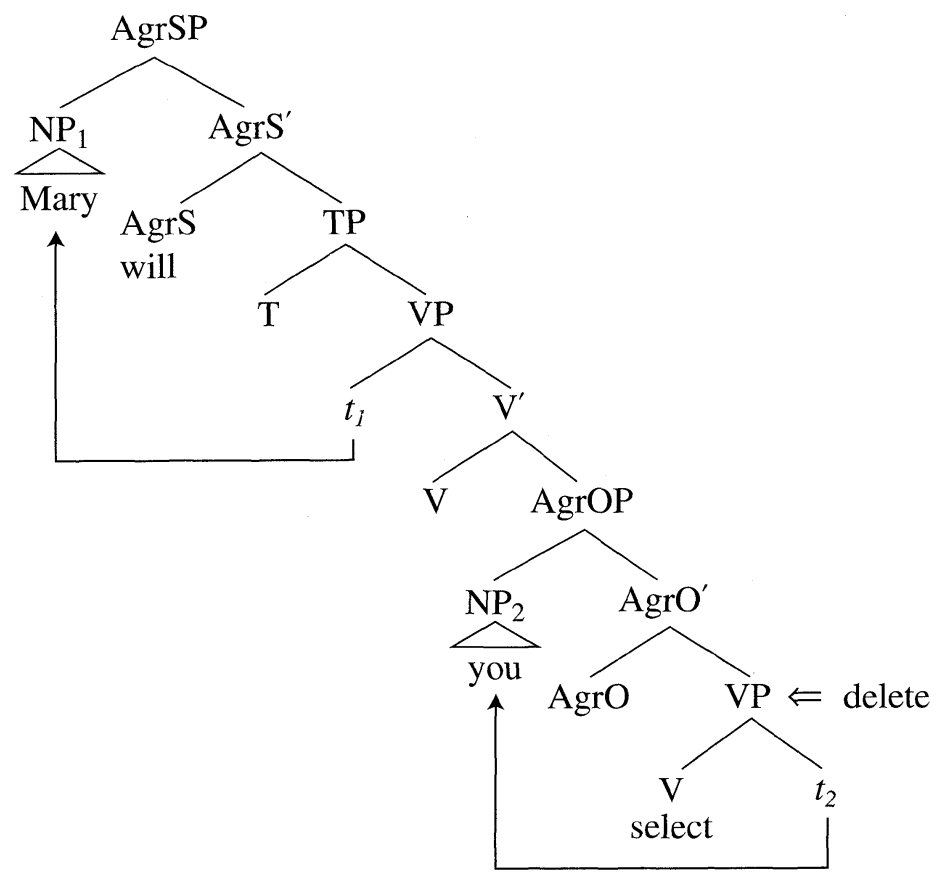

The lower verb select does stay at the base-generated position without moving to the upper V. Both the lower VP in (12) and that in (13) contain the trace of the object. Accordingly, they are considered to be identical for the operation of deletion and hence the lower VP in (13) is eliminated. Thus, Lasnik argues that Pseudogapping remnants move to Spec of AgrOP.

Although his analysis can account for the differences between Pseudogapping and HNPS illustrated in (8)-(11), it cannot explain why contrastive stress is put on the right side remnant in Pseudogapping, as illustrated in (11). The same problem turns up in the following sentences:

(14) a. ?Fred showed Mary's picture to his father, but Tom didn't show Mary's picture to his father.

b. *Fred showed Mary's picture to his father, but Tom didn't 
show Mary's picture to his father.

My informants find a contrast between (14a) and (14b). They report that (14a) is slightly degraded due to the repetition of the name Mary, but head and shoulders above (14b). The AgrO analysis assumes that the object Mary's picture occupies the same position, that is, Spec of AgrO, regardless of deletion. Thus, Lasnik's approach does not draw a necessary distinction between (14a) and (14b) and hence cannot account for the fact that a direct object moving to Spec of AgrO bears contrastive stress just in the Pseudogapping cases.

Notice that we cannot block (14b) by assuming a constraint on ellipsis which requires that an application of deletion target the largest constituent possible. This constraint would exclude (14b) because the lower VP is properly contained in the upper VP that is a possible target for deletion:

(15) Fred showed Mary's picture to his father, but Tom ${ }_{1}$ didn't [uP $t_{1}$ [AgrOP Mary's picture 2 [vP show $t_{2}$ to his father]] However, the constraint incorrectly excludes (16b, c):

(16) a. John could have been studying Spanish and Bill could Ever have [vp been [vp3 studying Spanish] too.

b. John could have been studying Spanish and Bill could [VP1 have [vP2 been [VP3 studying Spanish]] too.

c. John could have been studying Spanish and Bill could [VP1 have [VP2 been [vP3 studying Spanish]]] too.

(Potsdam (1998: 56))

The deleted structures in $(16 \mathrm{~b}, \mathrm{c})$ are properly contained in the larger structure, which, as (16a) shows, is itself a possible target for deletion. Consequently, we cannot supplement Lasnik's analysis with the dubious constraint in order to explain why NP moving to Spec of AgrOP should bear contrastive stress just in the Pseudogapping cases.

There is also a theoretical problem with the AgrOP analysis. Chomsky (1995: 349) claims that the existence of Agr-projections seem dubious because it does not provide "instructions" at the interfaces between the system of the language faculty and the performance system. In other words, unlike other functional categories (T, C, and D), Agr is present only for theory-internal reasons and hence should be discarded. Therefore, it is more theoretically desirable to provide an account of Pseudogapping without resorting to Agr-projections.

In summary, I have reviewed two previous analyses of Pseudogapping, and pointed out some problems with them. In the next sec- 
tion, maintaining the assumption that Pseudogapping remnants move out of the deleted VP, I will try to propose a new analysis.

\section{The Proposed Analysis of Pseudogapping}

3.1. Target and Trigger of PF-deletion

Before presenting my analysis, I will specify the framework of generative grammar that is necessary for the following argument. Generative grammar postulates that a linguistic expression is a pair $(\pi, \lambda)$ : $\pi$ is a Phonetic Form (PF) representation interpreted at the articulatory-perceptual interface. $\lambda$ is an Logical Form (LF) representation interpreted at the conceptual-intentional interface. This pair is derived from lexical items by a derivation that constructs syntactic structures. At some point of a derivation, the operation called Spell-Out applies to the structure $\Sigma$ already formed and strips away from $\Sigma$ those elements relevant only to $\pi$, leaving the residue $\Sigma_{\mathrm{L}}$, which is mapped to $\lambda$. $\Sigma$ itself is then mapped to $\pi$. The derivation that maps $\Sigma$ to $\pi$ is called the PF component, whereas the one that maps $\Sigma$ to $\lambda$ is the LF component. The pre-Spell-Out derivation is called the overt component (Chomsky (1995: 229)).

Given this framework, let us consider the derivation of Pseudogapping in (17):

(17) John will select Mary, and Bill will Susan.

I will suppose that the antecedent clause in (17) has the following structure that does not include Agr-projections:

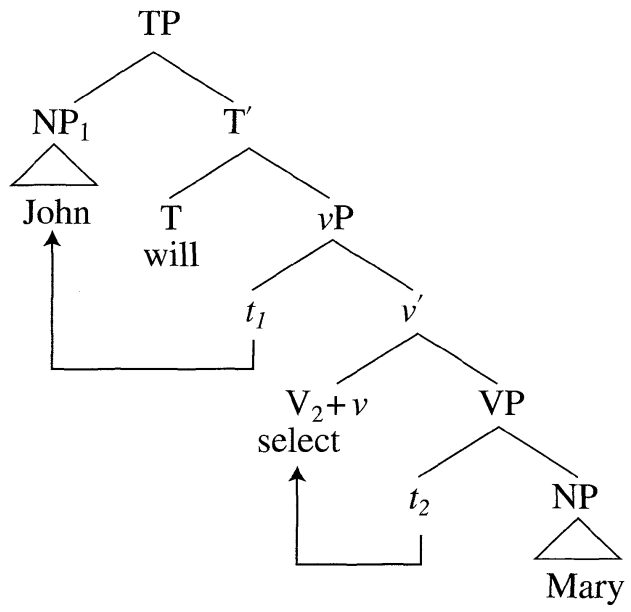


The upper VP is illustrated as $v \mathrm{P}$ whose head $v$ is called the light verb. The subject John is generated as Spec of $v \mathrm{P}$ and then raises to Spec of TP (Hale and Keyser (1993)). The verb select adjoins to $v$. The object Mary occupies the position inside VP. With respect to the elided clause, I will assume the following structure:

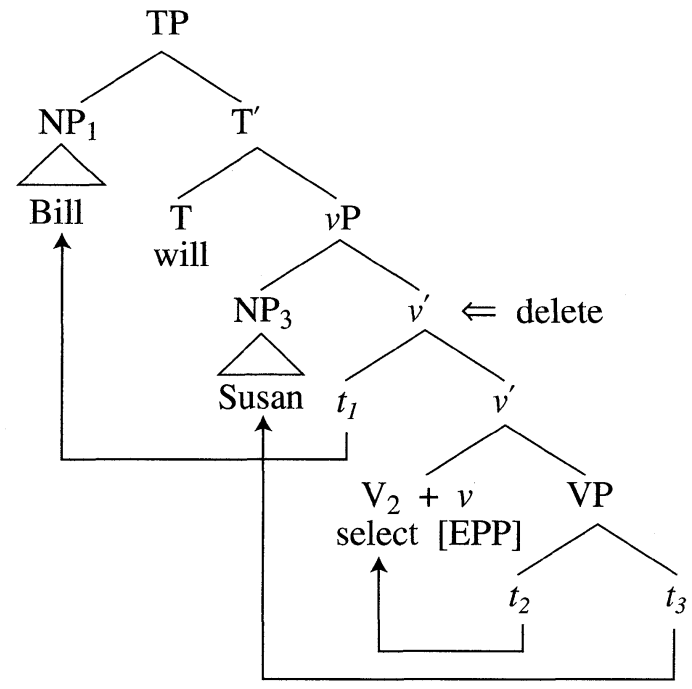

Unlike (18), the light verb in (19) has the Extended Projection Principle (EPP) feature, which forces Susan to move to its upper Spec before Spell-Out. Chomsky (2001:35) claims that the light verb is assigned an EPP-feature only if it has an effect on outcome. I assume that the EPP changes the word order and thus exercises an effect on the PF-representation in (19). Deletion applies to the $v^{\prime}$ excluding Susan in the PF component.

(19) assumes that an intermediate verbal projection is available for deletion (Chomsky (2001:39)). I suppose that when deletion applies to a projection of a lexical item, it should target the largest projection possible. ${ }^{2}$ In (19), the largest projection of $v$ is the $v \mathrm{P}$ containing Susan, but it cannot be elided because of the EPP-feature. The deletion of $v \mathrm{P}$ would yield the following structure:

(20) John will select Mary, and Bill $l_{1}$ will $\mathrm{E}_{\mathrm{vp}} \operatorname{Stusan}_{3}\left[_{v} t_{1} L_{v} L_{v}\right.$ $\mathcal{v}[\mathrm{EPP}]+$ select $\left._{2}\right]\left[\mathrm{VP} t_{2} t_{3}\right]$ ]

2 This constraint does not block the applications of deletion in (16) because they target projections of different lexical items. 
However, the same PF string as (20) is also derived from the following structure:

(21) John will select Mary, and Bill $l_{1}$ will $f_{v \mathrm{P}} t_{1}\left[\mathrm{~L}_{v}\left[v v+\right.\right.$ select $\left._{2}\right][\mathrm{vP}$ $t_{2}$ Susan ?

The $v$ in (21) has no EPP-feature so that Susan stays at the base-generated position. I will argue in the next subsection that (21) would yield the illegitimate LF-representation (see the discussion about (35)). Thus, in (19), the deletion of $v \mathrm{P}$ containing Susan would cancel an effect that the EPP-feature of the $v$ has on the PF outcome. Accordingly, the EPP-feature prevents the $v \mathrm{P}$ from undergoing deletion. Then, the target of deletion in (19) must be the second largest verbal projection, that is, the intermediate projection $v^{\prime}$.

Notice that the operation of deletion is obligatory in (19). Unless the $v^{\prime}$ is deleted, its output is ungrammatical:

(22) *John will select Mary, and Bill will Susan select.

I will attribute the obligatory deletion to the principle of Full Interpretation (FI), which requires that every element in a particular interface representation have an interpretation at that interface (Chomsky (1981, 1986, 1995)). In the case of a PF representation, all terminal nodes, which are structured bundles of syntactic features, must have a phonological value. Following Halle and Marantz (1993), I assume that a syntactic object has a phonological value if and only if it can be paired with a corresponding morphological matrix from the lexicon. This assumption preserves the possibility that the overt component can derive representations that are well formed in all respects except that they contain objects without morphophonological instantiations. I suppose that this is exactly what happens in (19). Susan moves to Spec of $v \mathrm{P}$ and passes a feature $\alpha$ to $v$ by Spec-head agreement. However, the lexicon of English lacks a morphological realization of the feature bundle corresponding to a $v_{[\alpha]}$ head. Consequently, a syntactic object containing $v_{[\alpha]}$ head has no phonological value and hence violates FI at a PF representation. The violation of FI is remedied by an application of deletion which may be construed as an instruction to "bypass" morphophonological instantiation. In other words, deletion of a constituent containing $v_{[\alpha]}$ would vacuously satisfy FI. Thus, deletion must apply to the second largest projection $v^{\prime}$ in (19). ${ }^{3}$

3 See Kennedy and Merchant (2000) for an argument that a violation of FI at a $\mathrm{PF}$ representation yields the effects of the Left Branch Constraint. 
3.2. Two-tier Conditions on an LF representation

Next, let us consider an LF representation of Pseudogapping. I will assume the following condition on deletion:

(23) The LF Identity Condition

At LF, the elided verb phrase must match with its antecedent in terms of the lexical content of the verb phrases involved as well as their syntactic form. (cf. Fiengo and May (1994)) (23) requires that an elided $v^{\prime}$ and its antecedent be identical at LF rather than PF. Some support for (23) comes from the following sentence:

(24) John [vP selected you], and Mary will fop select you too. (24) lets the verb of one inflectional type (selected) act as the antecedent for the verb bearing a different inflectional ending (select). We can understand (24) from (23) and the hypothesis that verbs and inflections come together in the PF component (Lasnik (1999a)). Given this hypothesis, the antecedent and elided verbs are in their stem form during the course of the syntactic derivation and hence the same element at LF:

(25) [TP John -ed [ $v_{\mathrm{P}}$ select you $]$ and [TP Mary will $\left[{ }_{\nu \mathrm{P}}\right.$ select you]] too.

Thus, (23) accounts for (24) straightforwardly.

Given (23), I suppose that the deleted projection in the PF component must be $\sqrt{ }$-marked as subject to (23) before Spell-Out (Chomsky (1995: 252)). This marking enables us to define identity between an elided $v^{\prime}$ and its antecedent in terms of LF, and also to maintain that an elided $v^{\prime}$ is derived by deletion in the PF component. Thus, this assumption gives (17) the following structure before Spell-Out:

(26) $\mathrm{John}_{4}$ will $\left[{ }_{\nu \mathrm{P}} t_{4}\right.$ select Mary], and Bill ${ }_{3}$ will $\left[{ }_{\nu \mathrm{P}} \operatorname{Susan}_{1}\left[v^{\prime} v t_{3}\right.\right.$ select $\left.t_{1}\right]$ ]

The antecedent of the deleted $v^{\prime}$ is the $v \mathrm{P}$ in the first clause. (26) violates (23) because the lexical content of the elided $v^{\prime}$ is different from that of the antecedent $v \mathrm{P}$. As a result, (23) requires Mary to move out of the $v \mathrm{P}$ in the LF component. For the purpose of exposition, I assume that Mary moves to TP:

(27) [TP Mary $2\left[\mathrm{TP} \mathrm{John}_{4}\right.$ will $\left[{ }_{\nu \mathrm{P}} t_{4}\right.$ select $\left.\left.\left.t_{2}\right]\right]\right]$, and Bill ${ }_{3}$ will $\left[{ }_{\nu \mathrm{P}}\right.$ Susan $_{1}\left[v^{\prime} v t_{3}\right.$ select $\left.\left.t_{1}\right]\right]$

Suppose that there are no bar levels and hence no distinction between $v^{\prime}$ and $v \mathrm{P}$ (Chomsky (1995: 249)). Then, the $v \mathrm{P}$ in the first clause can be the antecedent of the deleted $v^{\prime}$ in the second clause. These two verb 
phrases have the same lexical materials and syntactic structures. Consequently, (27) satisfies (23). ${ }^{4}$

The EPP-feature is assigned only to the $v$ of the second clause in (27). Suppose that the $v$ of the first clause also has the EPP-feature. Then, Mary moves out of the antecedent $\nu \mathrm{P}$ in the overt component:

(28) [Tе John 4 will [vP Mary $2\left[v^{\prime} t_{4}\left[v^{\prime} v_{[\alpha]}\right.\right.$ select $\left.\left.\left.t_{2}\right]\right]\right]$, and [тР Bill 3 will [vP $\operatorname{Susan}_{1}\left[v^{\prime} t_{3}\left[v^{\prime} v_{[\alpha]}\right.\right.$ select $\left.\left.\left.\left.t_{1}\right]\right]\right]\right]$

(28) satisfies (23) without resorting to LF-movement. However, (28) includes the two $v_{[\alpha]}$ heads because Mary and Susan raise to Spec of $\nu \mathrm{P}$ and assign a feature $\alpha$ to $v$ by Spec-head agreement. Therefore, the two $v$ 's including them must be elided to yield the following sentence:

(29) John will Mary and Bill will Susan.

One of my informants says that (29) seems fine as an answer to "Who will select who?" Accordingly, (29) is acceptable to the extent that elided material can be identified from the discourse. Thus, the corresponding phrase to a remnant in an elided clause moves out of an antecedent in the overt component as long as we can recognize what is deleted from the context.

While (23) prohibits an elided verbal projection and its antecedent from having different lexical material and syntactic structure, it is oblivious to indices. The question is why distinct movement traces are considered to be equivalent. To answer this question, I will supplement (23) with the semantic contrast condition proposed by Rooth (1992). This condition is based upon the 'alternative semantics for focus,' which

${ }^{4}$ (27) has the following LF structure under the copy theory of movement, which assumes that the trace left behind is a copy of the moved element (Chomsky (1993)):

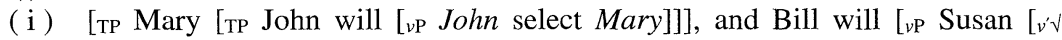
Bill select Susan]]

The italics mean the copies of the moved elements. The elided $v^{\prime}$ is not identical to its antecedent $v \mathrm{P}$ and hence (23) disallows the deletion of the $v^{\prime}$. To deal with this problem, I suppose that (i) is not the final LF representation of (17), and that (i) is converted to the following structure by the LF process to form an operator-variable chain:

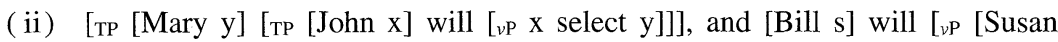
t] $\left[v^{\prime} v\right.$ s select t]]

In (ii), $\mathrm{x}, \mathrm{y}, \mathrm{s}$, and $\mathrm{t}$ are all variables and hence they are assumed to be identical elements in terms of (23). Thus, the proposed analysis is compatible with the copy theory of movement. 
assumes that the general function of focus is the evoking of alternatives. For example, let us look at the following sentence where the focused part of the sentence is marked by a subscript $F$ :

(30) $[\mathrm{John}]_{\mathrm{F}}$ wants coffee.

The subject receives prosodic prominence and this prosody reflects a syntactic representation in which the stressed constituent bears the focus feature F. This feature gives (30) not only an ordinary semantic value but also an additional focus semantic value: the focusing results in the emergence of a set of alternative individuals to John, and then yields the following set of propositions where $\mathrm{x}$ is an individual:

(31) $\quad\{\mathrm{p}: \exists \mathrm{x}$ [p $=$ that $\mathrm{x}$ wants coffee $]\}$

This is the focus semantic value of (30). In general, the focus semantic value of a LF $\beta$ is derived from $\beta$ 's ordinary semantic value by substituting alternative semantic values for the ordinary semantic values of F-marked constituents contained in $\beta$.

Focus semantic values play an important role in the following LF condition on deletion:

(32) a. A clause dominating an elided verb phrase must contrast appropriately with a clause dominating its antecedent.

b. A clause $\alpha$ contrasts appropriately with a clause $\beta$ iff for all assignments $\mathrm{g}$ :

(i) $[[\alpha]]^{\mathrm{g}} \neq[[\beta]]^{\mathrm{g}}$ and

(ii) $[[\alpha]]^{\mathrm{g}}$ is a member of the focus semantic value of $\beta$ with respect to $\mathrm{g}$.

(cf. Tomioka (1999: 232))

(32a) requires that an elided verb phrase be contained within a clause that contrasts with a clause dominating its antecedent. (32bi) prevents two clauses contrasted from having the same ordinary semantic value. (32bii) demonstrates that a LF $\alpha$ can be in contrast with a LF $\beta$ just in case the ordinary semantic value of $\alpha$ is an element of the focus value of $\beta$. (32bii) prevents the indices in antecedent and elided verb phrases from having different values unless they are borne by focused items.

With (32) in mind, let us get back to (17) and then consider why traces have different indices. It has the following LF representation:

(33) [тр Mary 2 [те $\mathrm{John}_{4}$ will [ ${ }_{\nu \mathrm{P}} t_{4}$ select $\left.\left.\left.t_{2}\right]\right]\right]$, and [Bill] $]_{\mathrm{F}, 3}$ will [vP [Susan $]_{\mathrm{F}, 1}\left[v^{\prime} v t_{3}\right.$ select $\left.\left.t_{1}\right]\right]$

Bill and Susan in the second clause contrast with John and Mary in the first one respectively. Accordingly, Bill and Susan receive prosodic prominence and then bear the focus feature $F$. Then, the second clause has the following focus semantic value where $\mathrm{x}$ and $\mathrm{y}$ are individuals: 


$$
\{\mathrm{p}: \exists \mathrm{x}, \mathrm{y}[\mathrm{p}=\text { that } \mathrm{x} \text { will select } \mathrm{y}]\}
$$

(34) has as its member the denotation of the first conjunct, that is, John will select Mary. Thus, (34) conforms to (32) and hence traces have different indices.

Notice that (32) does not always permit different indices of traces. It prevents the ungrammatical VP ellipsis in (35a) from having the LF representation in $(35 b)$ :

(35) a. *John will select Mary, and Bill will select Susan.

b. [тр Mary2 [тр John 4 will [vP $t_{4}$ select $\left.\left.t_{2}\right]\right]$ ], and [тр Susan $_{1}$

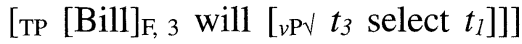

In (35b), Mary and Susan move out of the $v \mathrm{P}$ in the LF component so that the resultant representation meets (23). However, (35a) violates (32) because Susan is deleted in the PF component and hence cannot be a focused item. Consequently, the second clause of (35a) has the following focus semantic value where $\mathrm{x}$ is an individual:

(36) $\{\mathrm{p}: \exists \mathrm{x}[\mathrm{p}=$ that $\mathrm{x}$ will select Susan] (36) does not have as its member the denotation of the first conjunct. Thus, (32) disallows (36) and thus (35a) is unacceptable.

(32) predicts that Pseudogapping is ambiguous with respect to interpretation of a pronoun. This prediction holds. Consider the following example of Pseudogapping:

(37) I would show Mary,'s picture to her 1 father, but I wouldn't Jane's picture.

My informants agree that the second clause in (37) has two possible interpretations: either I wouldn't show Jane's picture to Mary's father or I wouldn't show Jane's picture to her own father. The former is called the strict reading and the latter the sloppy reading. These two readings follow from (32). (37) has the following LF-representation:

(38) [TP $[\text { Mary } 1 \text { 's picture }]_{2}$ [TP I would $\left[{ }_{\nu \mathrm{P}}\right.$ show $t_{2}$ to her ${ }_{1}$ father $]]$, but I [wouldn't $]_{\mathrm{F}}\left[\nu_{\mathrm{P}}\left[\left[\mathrm{Jane}^{\prime} \mathrm{s}\right]_{\mathrm{F}}, 3 \text { picture }\right]_{4}\left[v^{\prime} v\right.\right.$ show $t_{4}$ to her father]]

Contrasting with would and Mary, wouldn't and Jane receive prosodic prominence and then bear the focus feature F. (38) has a pronoun without an index and thus fails to indicate what denotations it gets. Suppose that the pronoun is a variable bound by Jane which undergoes Quantifier Raising (QR). Then, (38) leads to the structure (39), which in turn has focus semantic value (40):

(39) $\ldots$ but I [wouldn't $]_{\mathrm{F}}\left[{ }_{\nu \mathrm{P}}\left[\mathrm{Jane}^{\prime} \mathrm{s}\right]_{\mathrm{F}, 3}\left[_{\nu \mathrm{P}}\left[\mathrm{NP} t_{3} \text { picture }\right]_{4}\left[v^{\prime} v\right.\right.\right.$ show $t_{4}$ to her father]]] 
(40) $\{\mathrm{p}: \exists x y[\mathrm{p}=$ that I $\mathrm{x}$ show y's picture to y's father $]\}$ Variable $\mathrm{x}$ is a value of the same type as is denoted by an auxiliary verb, and y is an individual. (40) has as its member the denotation of the first conjunct, that is, I would show Mary's picture to Mary's father. Thus, (40) conforms to (32) and then yields the sloppy reading.

Next, let us consider the case where the pronoun in (38) retains the same index as in the antecedent:

(41) $\ldots$ but I [wouldn't $]_{\mathrm{F}}\left[{ }_{\nu \mathrm{P}}\left[\mathrm{Jane}^{\prime} \mathrm{s}\right]_{\mathrm{F}, 3}\left[{ }_{\nu \mathrm{P}}\left[\mathrm{NP} t_{3} \text { picture }\right]_{4}\left[v^{\prime} \vee\right.\right.\right.$ show $t_{4}$ to her 1 father]]]

Every assignment assigns Mary to the pronoun and thus (41) results in the following focus semantic value:

(42) $\{\mathrm{p}: \exists x y[p=$ that I x show y's picture to Mary's father] $\}$ One of the members of (42) is the denotation of the first conjunct. Therefore, (42) satisfies (32) and allows the strict reading.

Notice that (32) controls the possible interpretation of (37). My informants report that (37) does not mean 'I would show Mary's picture to her own father, but I wouldn't show Jane's picture to Susan's father.' This means that (37) cannot have the following LF structure:

(43) $\ldots$ but I [wouldn't $]_{\mathrm{F}}\left[{ }_{\nu \mathrm{P}}\left[\mathrm{Jane} \mathrm{J}^{\mathrm{s}}\right]_{\mathrm{F}, 3}\left[_{\nu \mathrm{P}}\left[\mathrm{NP} t_{3} \text { picture }\right]_{4}\left[v^{\prime} v\right.\right.\right.$ show $t_{4}$ to her 5 father]]]

Suppose that all assignments available in the utterance context assign Susan to the pronoun. Then, (43) leads to (44):

(44) $\{\mathrm{p}: \exists x y$ [p = that I $\mathrm{x}$ show y's picture to Susan's father] $\}$ The denotation of the first conjunct is not a proposition of the form, 'I $\mathrm{x}$ show y's picture to Susan's father.' As a result, (32) does not allow (37) to mean 'I would show Mary's picture to her own father, but I wouldn't show Jane's picture to Susan's father.' Thus, (32) constrains Pseudogapping in such a way that it filters out any illegal indexing to eliminate unacceptable interpretations. ${ }^{5}$

In summary, I have proposed that Pseudogapping involves movement of a remnant to Spec of $v \mathrm{P}$ in the overt component, followed by both PF-deletion of a verb projection $v^{\prime}$ excluding the remnant and LF-movement of a corresponding phrase out of its antecedent.

5 See Tomioka (1999) for the argument that (32) plays an important role in interpretation of VP ellipsis. 


\subsection{Deriving Contrast Effects}

Now, I will show that the proposed analysis of Pseudogapping resolves problems that Lasnik's analysis faces. First of all, unlike his analysis, my analysis accounts for Pseudogapping without resorting to Agr-projections that are assumed only for theory-internal reasons and hence should be discarded. In this respect, my analysis is theoretically superior to the AgrO approach.

Second, the proposed analysis also solves the problem of why a Pseudogapping remnant following an auxiliary verb is in a contrastive relation with a parallel term in the antecedent. Let us reconsider (14), repeated here as (45):

(45) a. ?Fred showed Mary's picture to his father, but Tom didn't show Mary's picture to his father.

b. *Fred showed Mary's picture to his father, but Tom didn't Mary's picture.

Assuming that a direct object moves to Spec of AgrO regardless of deletion, the AgrOP analysis cannot account for the contrast in (45).

The proposed analysis, by contrast, can distinguish (45a) from (45b) by assuming that Mary's picture occupies a different position. In (45a), the light verb has no EPP-feature so that Mary's picture stays at the base-generated position. In (45b), on the other hand, the EPP-feature of the light verb raises Mary's picture to Spec of $v \mathrm{P}$. Suppose that a phrase in Spec of $\nu \mathrm{P}$ is assigned "surface" interpretation including focus (Chomsky (2001: 35)). Then, Mary's picture in (45b) is interpreted as a focal phrase and hence must meet (32). However, it violates (32bi) because the remnant is identical to the corresponding phrase in the antecedent. Accordingly, the remnant cannot be in a contrastive relation with the parallel term in the antecedent so that (45b) is impossible. In contrast, Mary's picture in (45a) does not have to be interpreted as a focal phrase because it occupies the base-generated position rather than Spec of $v \mathrm{P}$. Consequently, it can be identical to the corresponding phrase in the antecedent so that (45a) is acceptable. Thus, the proposed analysis provides a straightforward account of (45) under the assumption that a phrase in Spec of $v \mathrm{P}$ is interpreted as focus.

\section{Further Arguments for the Proposed Analysis}

In the following two subsections, I will show that the proposed analysis explains two properties of Pseudogapping that are distinct from VP 
ellipsis. First, Pseudogapping degrades considerably in fronted adverbials, relative to VP ellipsis:

(46) a. Because John didn't, Mary interviewed Gingrich.

b. *Because John didn't Clinton, Mary interviewed Gingrich.

(Lasnik (1999b: 202))

Second, Pseudogapping shows a locality effect, whereas VP ellipsis does not (Fiengo and May (1994: 257)):

(47) a. Max claimed that he gave Lucy flowers before John did.

b. Max claimed that he gave Lucy flowers before John did chocolates.

(Lappin (1996: 152))

The elided material in (47a) can be either give Lucy flowers or claim that he gave Lucy flowers, while that in (47b) must be understood as give Lucy rather than claim that he gave Lucy. I will argue that these two properties of Pseudogapping follow from the proposed analysis and independently motivated conditions.

\subsection{Backward Deletion}

Let us consider the first difference between VP ellipsis and Pseudogapping: the availability of backward ellipsis. Lasnik (1999b) suggests the possibility of attributing the difference to the discourse component, but does not give a specific analysis. I will explain the highly constrained nature of backward Pseudogapping by a condition of sentence processing.

Before starting my argument, let us consider the processes involved in the interpretation of the following sentences where $\varnothing$ indicates an elided element.

(48) a. Mary interviewed Gingrich because John didn't $\emptyset$. [ $\varnothing=$ interview Gingrich]

b. *Mary did $\varnothing$ because John didn't interview Gingrich. [ $\varnothing=$ interview Gingrich]

(49) a. Mary interviewed Gingrich because John didn't $\varnothing$ Clinton. $\quad[\varnothing=$ interview $]$

b. *Mary did $\varnothing$ Gingrich because John didn't interview Clinton. $\quad[\varnothing=$ interview $]$

These sentences show that elided elements must follow their antecedents. We can understand this fact in terms of the processes involved in left-to-right interpretation of ellipsis. Interpretation of the (a) sentences is running smoothly because the processor can detect an antecedent in the left context when it recognizes deleted material. This 
conforms to the way we process sentences. Psychological evidence suggests that the processor tends to interpret each word as soon as it encounters that word (Frazier and Clifton (1996)). Let us call this the principle of immediacy of interpretation/processing. This principle requires the processor to have access to an antecedent before it encounters a deleted phrase in order to interpret ellipsis. In the (a) examples, the antecedent is detectable in the left context of the elided phrase. Accordingly, the processing of these sentences satisfies the immediacy principle and thus the processor can interpret them without processing delay. In the (b) sentences, on the other hand, the processor does not know the antecedent at the point where it encounters the deleted element. When the processor fails to find the antecedent in the preceding context, it must wait for its subsequent appearance. As a result, the interpretation of these sentences is delayed and hence does not satisfy the immediacy principle. Thus, we can attribute the contrast between the (a) sentences and the (b) ones to the condition of sentence processing that requires the processor to interpret sentences immediately.

This condition of sentence processing allows an elided element to precede its antecedent only if the processor can expect the antecedent in the following context at a very early point of the parse. This expectation is possible in (46a). Although the deleted phrase precedes its antecedent, (46a) does not violate the condition of sentence processing. This is because the initial subordination marker Because has a great influence upon the processing process. This marker at once indicates the onset of the subordinate clause and signals the subsequent appearance of the main clause. Therefore, it enables the processor, at a very early point of the parse, to predict the antecedent in the following context. In other words, the subordination marker makes it possible for the processor to "pre-compute" the antecedent before obtaining the relevant information. This means that the processor can cancel the immediacy principle as long as it has been assured of interpretive success at some later point. Thus, the backward VP ellipsis in (46a) is tolerated since the processor has had the subsequent occurrence of the antecedent clause guaranteed thanks to the initial subordinator.

Now let us turn to the backward Pseudogapping in (46b). Like (46a), the subordination marker at the beginning of the subordinate clause permits the processor to expect the antecedent in the following context and hence (46b) is predicted to be permitted, contrary to fact. In order to account for (46b), we have to suppose that sentence process- 
ing involves not only semantic decisions such as the search for an antecedent of an elided phrase, but also a structural analysis of a sentence. Following Frazier and Clifton (1996), I suppose that the processor quickly gives a single syntactic analysis to an ambiguous fragment of a temporarily ambiguous sentence without waiting for evidence pointing to the correctness of one analysis or the other. Specifically, I assume that a structural analysis of a sentence is based upon the following structural parsing condition:

(50) Minimal Attachment

Do not postulate any potentially unnecessary nodes.

(Frazier and Clifton (1996: 9)) (50) is considered as one particular instantiation of the general parsing principle of immediate interpretation. (50) requires the processor to combine each new word with the existing structure using the smallest number of new nodes because node postulation takes time.

Given (50), let us consider the sentence processing of (46b) step by step. The processor assigns it the following syntactic analysis at some point of the processing:

(51) $\left[\mathrm{PP}\right.$ Because $\left[\mathrm{TP}\right.$ John $\left[\mathrm{T}^{\prime}\right.$ didn't $\left[{ }_{\nu \mathrm{P}} \ldots\right.$

After (51) the processor expects that a verb will follow didn't. However, against expectation, it encounters the noun Clinton and then judges that a verbal phrase is deleted. On the basis of this judgment, the processor considers two options to relate Clinton to (51): one is to classify it as a subordinate element by locating it in Spec of the $\nu \mathrm{P}$ in the subordinate clause, and the other is to group it with the matrix elements:

(52) a. [PP Because [TP $\operatorname{John}_{1}\left[\mathrm{~T}^{\prime}\right.$ didn't ${ }_{{ }_{\nu \mathrm{P}}}$ Clinton $_{2}\left[v^{\prime} t_{1} v\left[{ }_{\mathrm{vP}} \mathrm{V}\right.\right.$ $\left.\left.\left.\left.\left.t_{2}\right]\right]\right]\right] 1\right][$ Tт $\ldots$

b. [PP Because [TP $\mathrm{John}_{1}\left[\mathrm{~T}^{\prime}\right.$ didn't $\left.\left.\left.\left[\begin{array}{lllll}\mathrm{\nu P} & t_{1} & v & {[\mathrm{vp}} & \mathrm{V}\end{array}\right]\right]\right]\right]$ [TP Clinton ....

The principle of immediate processing requires the processor to make the prompt decision between (52a) and (52b) at this point without delaying the decision until the end of the sentence. Locating Clinton in Spec of $v \mathrm{P}$ creates the additional node $v^{\prime}$ that makes (52a) more complex than (52b). Accordingly, (50) requires the processor to select the minimal structure in (52b). However, when the next word Mary arrives, it informs the processor that $(52 \mathrm{~b})$ is incorrect. The processor must revise (52b) and thus backtrack to reinterpret the sentence. Such backtracking with revision of syntactic structure is costly for the proces- 
sor. Consequently, the processing difficulty that is inherent in the structural properties rather than the particular words involved provides major factors that motivate the disuse of backward Pseudogapping. ${ }^{6}$

Notice that (49a) does not create the same kind of processing difficulty. When the processor encounters the word Clinton, it has only one option to combine the word with the existing structure by putting it in the Spec of $v \mathrm{P}$ in the embedded clause. Therefore, Clinton in (49a) produces no ambiguity about a structural analysis of a sentence.

In summary, I have shown that in backward Pseudogapping, the processor incorrectly analyzes the right side remnant as a matrix element and then has to revise the initial analysis and backtrack to reinterpret a sentence. I have argued that such backtracking with revision of syntactic structure leads to processing difficulty that underlies the unavailability of backward Pseudogapping.

\subsection{A Locality Effect}

Next, let us turn to the locality effect of Pseudogapping in (47). I will derive the locality effect from (23) and the distinction between the movement in the overt component and that in the LF component.

Let us consider the derivation of (47b). It has the following structure in the overt component:

(53) $\left[\mathrm{TP}\right.$ Max -ed $\left[{ }_{\nu \mathrm{P}}\right.$ claim that $\left[\mathrm{TP}_{\mathrm{TP}} \mathrm{he}_{3}-\mathrm{ed}\left[{ }_{\nu \mathrm{P}} t_{3}\right.\right.$ give Lucy flow-

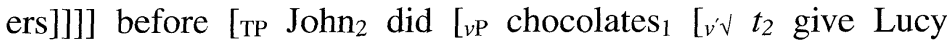
$\left.\left.\left.t_{1}\right]\right]\right]$

The corresponding phrase flowers moves out of the antecedent to yield the following structure:

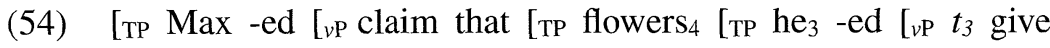
Lucy $\left.\left.\left.\left.\left.t_{4}\right]\right]\right]\right]\right]$ before [TP $\mathrm{John}_{2}$ did [ ${ }_{\nu \mathrm{P}}$ chocolates ${ }_{1}\left[v^{\prime} v t_{2}\right.$ give Lucy $\left.\left.\left.t_{l}\right]\right]\right]$

${ }^{6}(50)$ conflicts with another parsing condition:

(i) Late Closure

If grammatically permissible, attach new items into the clause or phrase currently being processed (i.e., the clause or phrase postulated most recently).

(Frazier and Clifton (1996: 9))

Since (i) requires Clinton to be grouped with subordinate elements rather than matrix ones, it selects (52a) over (52b). To prevent this conflict, I will assume with Frazier and Clifton (1996: 201 note 4) that Minimal Attachment is ranked over Late Closure. 
Since the $v \mathrm{P}$ in the first clause are syntactically identical to the elided $v^{\prime}$, (23) allows the former to be the antecedent of the latter. As a result, the elided phrase can be interpreted as give Lucy.

Next, let us consider the case where the ellipsis site in (47b) is understood as claim that he gave Lucy. In this case, chocolates moves to Spec of the matrix $v \mathrm{P}$. Given locality of movement, this movement must go through CP. Furthermore, since the movement applies in the overt component, it must meet the extension condition, which requires that a syntactic operation apply at the root. Hence, the movement happens at the time the CP is constructed. (55) illustrates the stepwise derivation of the second clause of $(47 \mathrm{~b})$ :

(55) a. [

b. [CP chocolates ${ }_{1}\left[\mathrm{C}^{\prime}\right.$ that [TP he -ed [ ${ }_{\nu \mathrm{P}}$ give Lucy $\left.\left.\left.\left.t_{1}\right]\right]\right]\right]$

c. ${ }_{\nu \mathrm{P}}$ John claim $\left[\mathrm{CP}\right.$ chocolates ${ }_{1}\left[\mathrm{C}^{\prime}\right.$ that ${ }_{\mathrm{TP}}$ he $-\mathrm{ed}{ }_{\nu \mathrm{P}}$ give Lucy $\left.t_{1}\right]$ ]1]]

d. [vP chocolates ${ }_{1}\left[v^{\prime}\right.$ John claim $\left[{ }_{\mathrm{CP}} t_{1}^{\prime}\left[\mathrm{C}^{\prime}\right.\right.$ that $\left[\mathrm{TP}\right.$ he $-\mathrm{ed}\left[{ }_{\nu \mathrm{P}}\right.$ give Lucy $\left.\left.\left.\left.\left.\left.t_{1}\right]\right]\right]\right]\right]\right]$

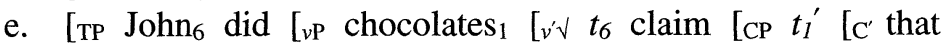
[TP he -ed [vp give Lucy $\left.t_{1}\right]$ ] ] ]]]]

From (55a) to (55b), the movement of chocolates applies at the root CP and hence projects the new category. This movement is substitution (Chomsky (1995: 248)).

On the other hand, the antecedent clause of (47b) has the following structure in the overt component:

(56) $\left[\mathrm{TP}_{\mathrm{TP}} \mathrm{Max}_{5}\right.$-ed [ ${ }_{\nu \mathrm{P}} t_{5}$ claim [CP that [TP he -ed [ ${ }_{\nu \mathrm{P}}$ give Lucy flowers]]]]]

The corresponding phrase flowers moves out of the matrix $v \mathrm{P}$ in the LF component to yield the following structure:

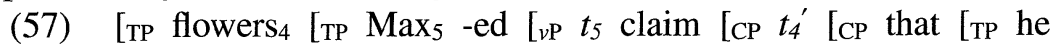
-ed [vP give Lucy $\left.\left.\left.t_{4}\right]\right]\right]$ ] ] ]]

Locality of movement requires that the movement of flowers go through $\mathrm{CP}$. When the movement takes place, the $\mathrm{CP}$ is already embedded under the matrix clause. Accordingly, the movement does not project a new category, but it forms the two-segment category of CP. This movement is adjunction (Chomsky (1995: 248)). Thus, the structure of the elided clause is different from that of the antecedent: 
(58) a. the antecedent clause

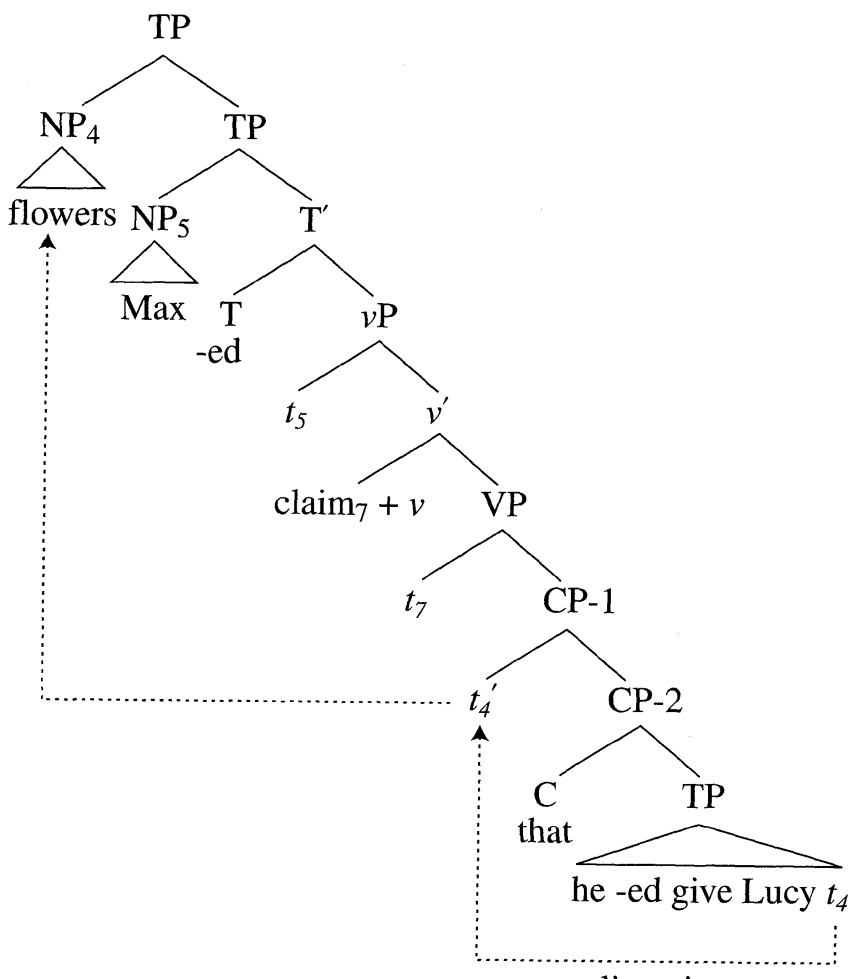

adjunction 
b. the elided clause

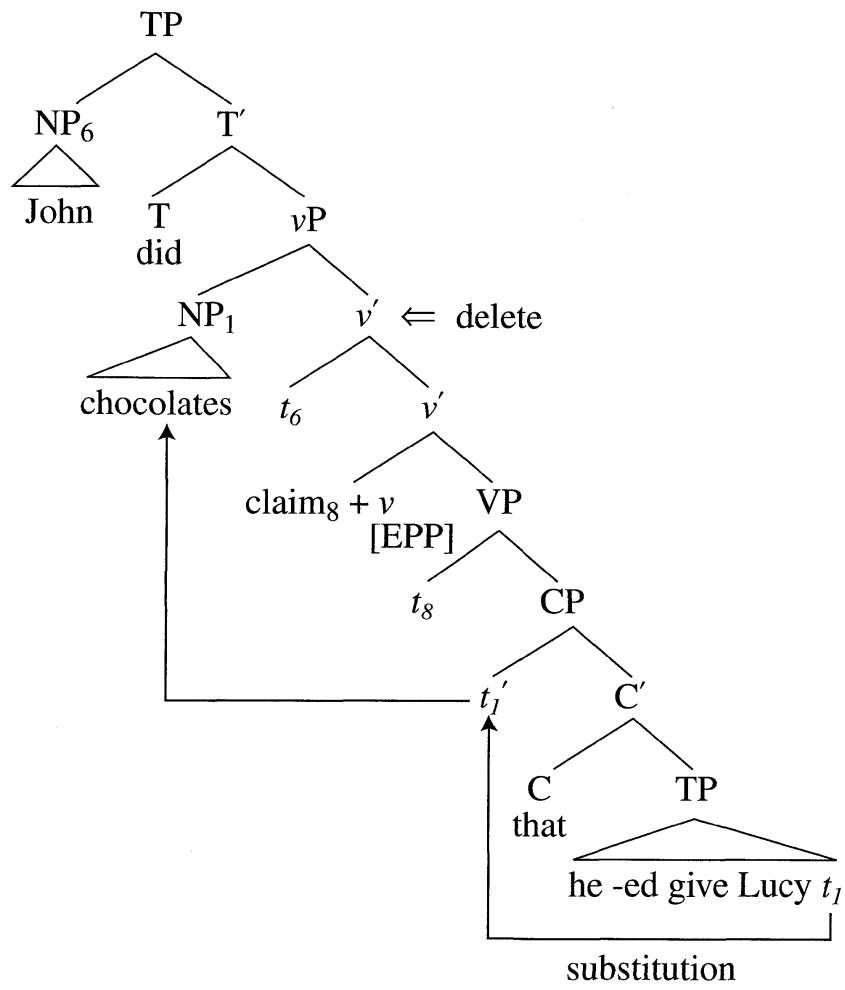

In (58), a solid line indicates the movement in the overt component and a dotted line shows that in the LF component. CP-1 and CP-2 in (58a) are two segments of the category CP. By contrast, $\mathrm{CP}$ and $\mathrm{C}^{\prime}$ in (58b) are two independent categories. Consequently, (23) prevents the $v \mathrm{P}$ in (58a) from being the antecedent of the deleted $v^{\prime}$ in (58b). Thus, the locality effect of Pseudogapping follows from (23) and the distinction between substitution and adjunction.

The proposed analysis makes the interesting prediction that like Pseudogapping, VP ellipsis also shows the locality effect when movement takes place from the deleted VP. This prediction is borne out:

(59) a. ?I know Abby took Greek, but YOU don't know which language ${ }_{1}$ she did take $t_{t}$.

b. *I know Abby said that she would take Greek, but YOU don't know which language ${ }_{1}$ she did say that she would take $t_{t}$. 
My informants find a clear contrast between (59a) and (59b)..$^{7}$ (59a) has the following LF representation:

(60) I know [TP Greek 2 [тP $\mathrm{Abby}_{3}$-ed [ ${ }_{\nu \mathrm{P}} t_{3}$ take $\left.\left.\left.t_{2}\right]\right]\right]$ but YOU don't know [CР which language ${ }_{1}\left[\mathrm{TP}_{\mathrm{P}} \mathrm{she}_{4} \operatorname{did}\left[{ }_{\nu \mathrm{P}} \vee t_{4}\right.\right.$ take $\left.\left.\left.t_{1}\right]\right]\right]$

The two $\nu \mathrm{Ps}$ are similar in terms of lexical content and syntactic structure so that (60) satisfies (23). On the other hand, (59b) has the following LF representation:

(61) ${ }_{\mathrm{TP}} \mathrm{Greek}_{2}\left[\mathrm{TP}_{\mathrm{TP}} \mathrm{I}_{3}\right.$-ed ${ }_{{ }_{\nu \mathrm{P}}} t_{3}$ say $\left[\mathrm{CPP}_{\mathrm{CP}} t_{2}{ }^{\prime}\left[{ }_{\mathrm{CP}-2}\right.\right.$ that she would take $\left.\left.\left.\left.t_{2}\right]\right]\right]\right]$ but YOU don't know [CP which language ${ }_{1}$ [TP $\mathrm{she}_{4} \operatorname{did}\left[{ }_{\nu \mathrm{P} \vee} \mathrm{t}_{4}\right.$ say [cp $t_{i}^{\prime}$ [ $\mathrm{C}^{\prime}$ that she would take $t_{l}$ ] ] ]]]

The deleted phrase involves the two different categories, that is, $\mathrm{C}^{\prime}$ and CP. In contrast, the antecedent contains the two-segment category of CP. Therefore, (61) violates (23) and hence (59b) is ungrammatical.

As expected, my informants judge that the locality effect of VP ellipsis disappears when wh-movement takes place in the antecedent clause as well: ${ }^{8}$

(62) I know [CP which language ${ }_{1}$ [TP Abby -ed [ ${ }_{\nu \mathrm{P}}$ say [ $\mathrm{CP}_{\mathrm{CP}_{1}}{ }^{\prime}\left[\mathrm{C}^{\prime}\right.$ that [тр she would take $\left.\left.\left.\left.\left.t_{1}\right]\right]\right]\right]\right]$, but YOU don't know [СР which language ${ }_{2}$ [TP she did $f_{v p}-s a y L_{C P} t_{2}^{\prime} f_{e}$ that $E_{T P}$ she would take $\left.\mathrm{t}_{2}\right]$ ]l]

(62) satisfies (23) because the elided $v \mathrm{P}$ matches with its antecedent. As a result, (62) does not show the locality effect. Thus, the proposed analysis provides a unified account of the locality effects of both Pseudogapping and VP ellipsis.

In summary, I have attributed the locality effect of Pseudogapping to (23) and the distinction between substitution and adjunction. Furthermore, I have shown that the proposed analysis explains the locality effect that standard VP ellipsis shows when movement takes place from the deleted VP. ${ }^{9}$

${ }^{7}$ Lasnik (2001: 317-318) makes a similar observation.

8 Fox and Lasnik (2003: 151) state a similar judgment.

9 The locality effect does not hold for the following type of ellipsis called Sluicing:

(i) I know that John said that Mary read a certain book, but I don't know which one.

The interrogative clause is reduced to containing only the wh-phrase which one, which corresponds to a certain book in the antecedent clause. The ellipsis site can be understood as John said that Mary read. There are at least two approaches to 


\subsection{Objects of Prepositions}

Finally, I will argue that the proposed analysis accounts for the following correlation between Pseudogapping and Pseudopassive pointed out by Lasnik (1999a: 157-158):

(63) a. John spoke to Bill and Mary should Susan.

b. Bill $l_{1}$ was spoken to $t_{l}$ by John.

(64) a. *John stood near Bill and Mary should Susan.

b. ${ }^{*}$ Bill $_{1}$ was stood near $t_{1}$ by John.

This correlation illustrates that the object of a preposition can make an acceptable Pseudogapping remnant only when reanalysis applies to the preposition and the preceding verb so that the preposition forms a constituent with the verb rather than the following object. I will derive the distinction between (63a) and (64a) from (23) and some auxiliary assumptions about reanalysis.

I assume that preposition and verb become "reanalyzed" as one verb only when the former moves to the latter in the overt component. This assumption gives the second clause of (63a) the following structure:

account for (i). The first is to assume that Sluicing involves no movement or PF deletion, but LF copying (Chung, Ladusaw and McClosky (1995)). The second is to assume that although Sluicing is formed by PF deletion, it is not subject to the LF identity condition (cf. Merchant (2001)). This approach imposes only the semantic contrast condition in (32) on Sluicing. I will not pursue the detailed work necessary to decide which of the two approaches is correct, and thus leave further investigation of the issue for future research. 
(65)

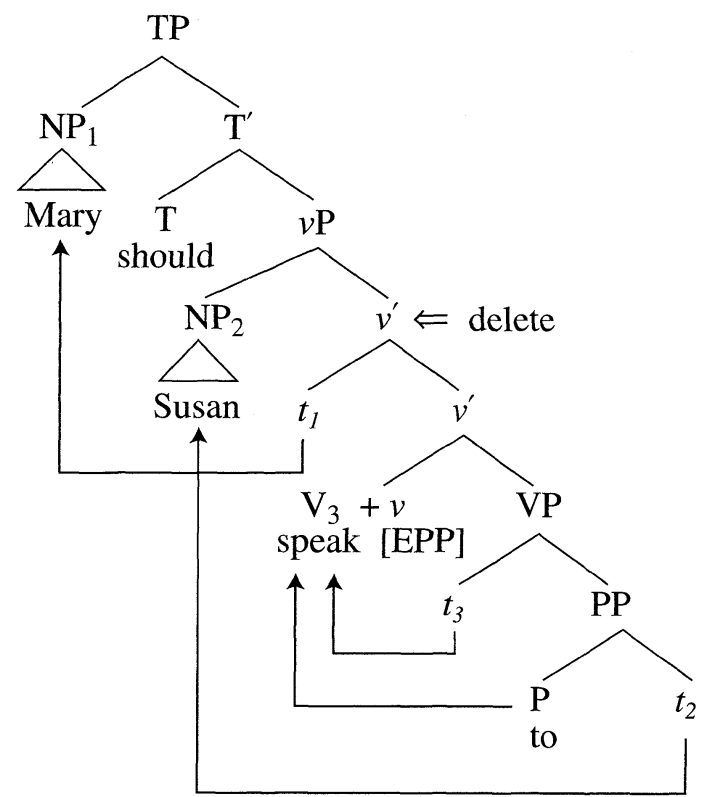

The preposition to moves to speak to form a constituent. On the other hand, the first clause of (63a) has the following structure:

(66)

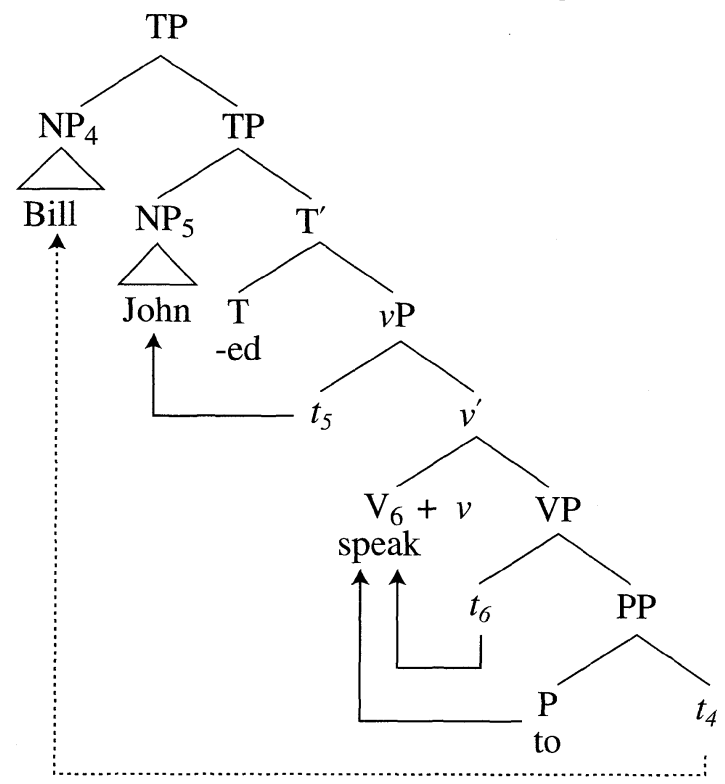

Bill undergoes an adjunction to TP in the LF component. Since the $v \mathrm{P}$ 
in (66) is syntactically identical to the elided $v^{\prime}$ in (65), (23) allows the former to function as the antecedent of the latter. Therefore, (63a) is grammatical.

Next, let us turn to (64a). Suppose that there exists a functional category intervening between near and stand, and that this category prohibits the former from moving to the latter. For expository convenience, I will call the category the light preposition $p$. Locality of movement requires that the object of near move through Spec of $p \mathrm{P}$ to Spec of $v$ P. Then, the elided clause of (64a) has the following structure:

(67)

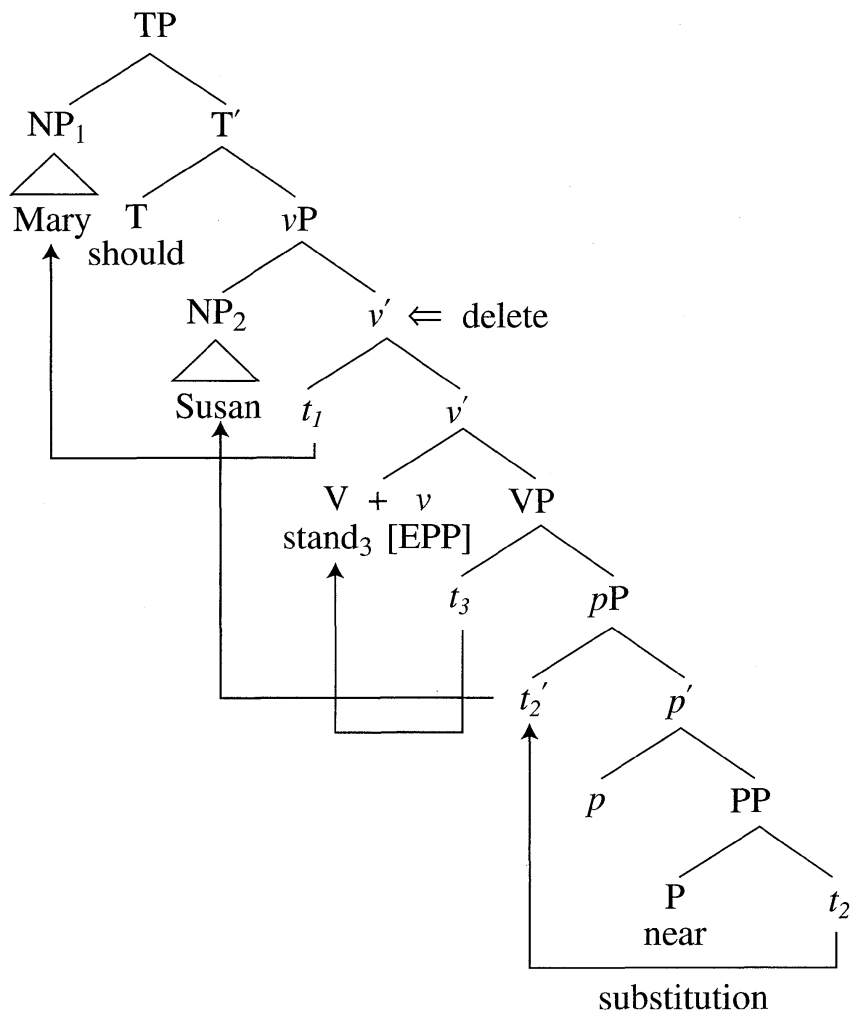

Since the movement of Susan applies in the overt component, it is substitution and hence projects the two different categories ( $p^{\prime}$ and $p \mathrm{P}$ ). On the other hand, the antecedent clause of (64a) has the following structure: 
(68)

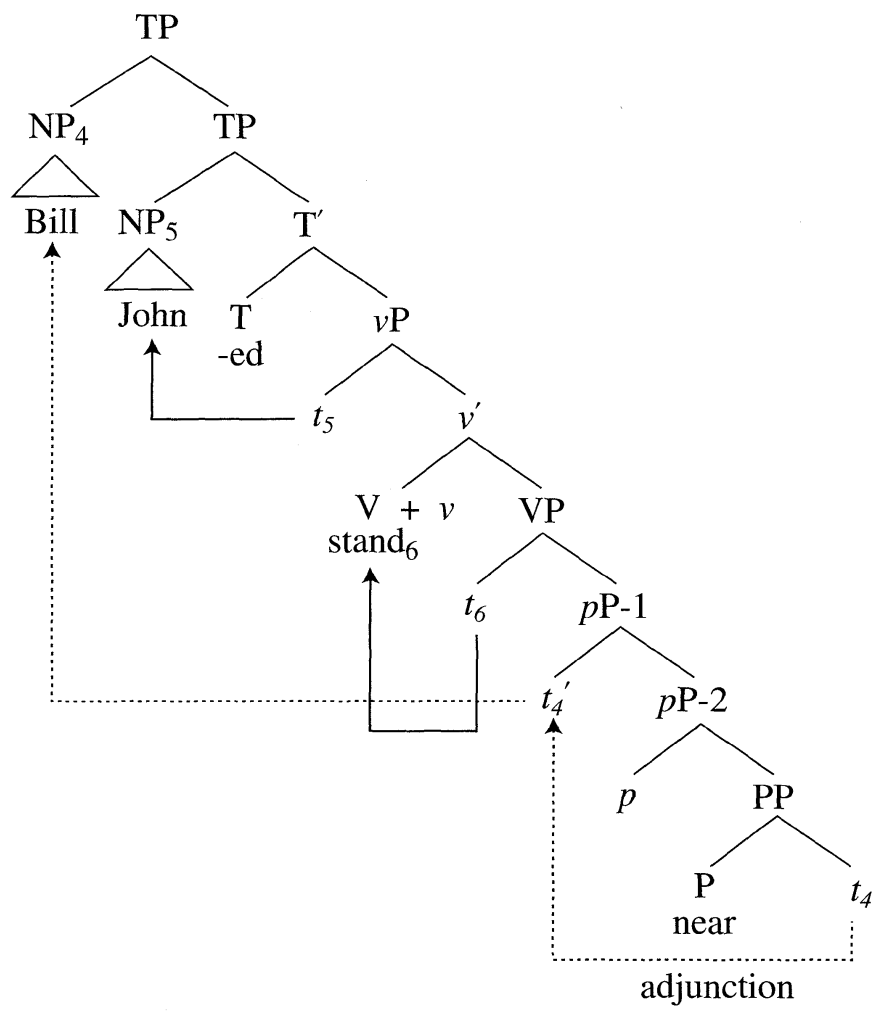

Locality of movement requires Bill to go through $p \mathrm{P}$ on the way to TP. Since the movement takes place in the LF component, it is the adjunction that forms the two-segment category of $p \mathrm{P}(p \mathrm{P}-1$ and $p \mathrm{P}-2)$. The resultant structure of $p \mathrm{P}$ in (68) is different from that in (67) so that (23) disallows the $v \mathrm{P}$ in (68) from being the antecedent of the elided $v^{\prime}$ in (67). Accordingly, (64a) is ungrammatical. Thus, the proposed analysis derives the distinction between (63a) and (64a) from (23) and the difference of whether a functional category intervenes between a preposition and a verb.

\section{Summary}

In this article, I have proposed that Pseudogapping involves movement of a remnant to Spec of $\nu \mathrm{P}$ in the overt component, followed by both PF-deletion of a verb projection excluding the remnant and LFmovement of a corresponding phrase out of its antecedent. This pro- 
posal provides a straightforward account of the contrast effects of Pseudogapping. Furthermore, the proposed analysis explains the two properties of Pseudogapping that are distinct from VP ellipsis. The unavailability of backward Pseudogapping follows from the immediacyof-processing condition. The locality effect of Pseudogapping is attributed to the distinction between substitution and adjunction. I have also deduced the correlation between Pseudogapping and Pseudopassive from a functional category intervening between a preposition and a verb. If the arguments along these lines are valid and the conclusions arrived at turn out to be sound and fruitful, this article provides empirical grounds for analyzing Pseudogapping as a special case of VP ellipsis and thus contributes a simplified design for language.

\section{REFERENCES}

Baltin, Mark (2003) "The Interaction of Ellipsis and Binding: Implications for the Sequencing of Principle A," Natural Language \& Linguistic Theory 21, 215-246.

Chomsky, Noam (1981) Lectures on Government \& Binding: The Pisa Lectures, Mouton de Gruyter, Berlin.

Chomsky, Noam (1986) Barriers, MIT Press, Cambridge, MA.

Chomsky, Noam (1991) "Some Notes on Economy of Derivation and Representation," Principles and Parameters in Comparative Grammar, ed. by Robert Freidin, 417-454, MIT Press, Cambridge, MA. [Reprinted in The Minimalist Program, 1995, MIT Press, Cambridge, MA.]

Chomsky, Noam (1993) "A Minimalist Program for Linguistic Theory," The View from Building 20: Essays in Linguistics in Honor of Sylvain Bromberger, ed. by Kenneth Hale and Samuel Jay Keyser, 1-52, MIT Press, Cambridge, MA. [Reprinted in The Minimalist Program, 1995, MIT Press, Cambridge, MA.]

Chomsky, Noam (1995) The Minimalist Program, MIT Press, Cambridge, MA. Chomsky, Noam (2001) "Derivation by Phase," Ken Hale: A Life in Language, ed. by Michael Kenstowicz, 1-52, MIT Press, Cambridge, MA.

Chung, Sandra, William Ladusaw and James McCloskey (1995) "Sluicing and Logical Form," Natural Language Semantics 3, 1-44.

Fiengo, Robert and Robert May (1994) Indices and Identiy, MIT Press, Cambridge, MA.

Fox, Danny and Howard Lasnik (2003) "Successive-Cyclic Movement and Island Repair: The Difference between Sluicing and VP-Ellipsis," Linguistic Inquiry 34, 143-154.

Frazier, Lyn and Charles Clifton, Jr. (1996) Construal, MIT Press, Cambridge, 
MA.

Hale, Kenneth and Samuel Jay Keyser (1993) "On Argument Structure and the Lexical Expression of Syntactic Relations," The View from Building 20: Essays in Linguistics in Honor of Sylvain Bromberger, ed. by Kenneth Hale and Samuel Jay Keyser, 53-109, MIT Press, Cambridge, MA.

Halle, Morris and Alec Marantz (1993) "Distributed Morphology and the Pieces of Inflection," The View from Building 20: Essays in Linguistics in Honor of Sylvain Bromberger, ed. by Kenneth Hale and Samuel Jay Keyser, 111176, MIT Press, Cambridge, MA.

Jayaseelan, Karattuparambil A. (1990) "Incomplete VP Deletion and Gapping," Linguistic Analysis 20, 64-81.

Kennedy, Christopher and Jason Merchant (2000) "Attributive Comparative Deletion," Natural Language \& Linguistic Theory 18, 89-146.

Koizumi, Masatoshi (1995) Phrase Structure in Minimalist Syntax, Doctoral dissertation, MIT.

Lappin, Shalom (1996) "The Interpretation of Ellipsis," The Handbook of Contemporary Semantic Theory, ed. by Shalom Lappin, 145-175, Blackwell, Oxford.

Lasnik, Howard (1999a) Minimalist Analysis, Blackwell, Oxford.

Lasnik, Howard (1999b) "On Feature Strength: Three Minimalist Approaches to Overt Movement," Linguistic Inquiry 34, 197-217. [Reprinted in Minimalist Investigations in Linguistic Theory, 2003, 83-102, Routledge, London and New York.]

Lasnik, Howard (2001) "When Can You Save a Structure by Destroying It?" NELS 31, 301-320.

Levin, Nancy S. (1979) Main-Verb Ellipsis in Spoken English, Doctoral dissertation, Ohio State University. [Published by Garland, New York and London, 1986.]

Merchant, Jason (2001) The Syntax of Silence: Sluicing, Islands, and the Theory of Ellipsis, Oxford University Press, Oxford.

Potsdam, Eric (1998) Syntactic Issues in the English Imperative, Garland, New York.

Rooth, Mats (1992) "Ellipsis Redundancy and Reduction Redundancy," Proceedings of the Stuttgart Ellipsis Workshop.

Sag, Ivan (1976) Deletion and Logical Form, Doctoral dissertation, MIT. [Published by Garland, New York and London, 1980.]

Shima, Etsuro (2003) "A Locality Effect of Pseudogapping," English and English-American Literature 38, 17-32, Yamaguchi University.

Shima, Etsuro (2005) "A Sloppy Identity Puzzle of Pseudogapping," Journal of the Literary Society of Yamaguchi University 55, 129-140, The Literary Society of Yamaguchi University.

Tomioka, Satoshi (1999) "A Sloppy Identity Puzzle," Natural Language Semantics 7, 217-241. 
Faculty of Humanities

Yamaguchi University

Yoshida 1677-1

Yamaguchi 753-8540

e-mail: eshima@yamaguchi-u.ac.jp 